\title{
Impact of the Global Climate on Building Energy Consumption Using Very High Resolution Urban Climate Atlas
}

\author{
Roberto San José, Juan L. Pérez, Libia Pérez, Rosa M. González, Julia Pecci, Antonio Garzón, and Marino Palacios
}

\begin{abstract}
The impact of future climate scenarios on building energy consumption for ventilation, heating and cooling was investigated using very high spatial resolution urban meteorological data over Madrid and London areas and considering the Representative Concentration Pathway 4.5 and 8.5 IPCC climate scenarios. To quantify the impact, we use very high resolution urban meteorological dataset produced by a dynamical downscaling process. This paper also presents the modeling system to make a dynamical downscaling process for urban climate information. The outputs of the Community Climate System Model (CCSM) provides future climate scenarios, and its coupling with Weather Research and Forecasting and Chemical (WRF/Chem) model. The output from the $\mathrm{WRF} / \mathrm{Chem}$ model at $1 \mathrm{~km}$ resolution is used to drive a micro-scale computational fluid dynamics model, MICROSYS. The final weather data was used in building energy simulations by EnergyPlus model. Sixteen types of buildings were simulated of each of the two cities under two possible climate scenarios for years 2011 and 2100 . There is a net increase in energy consumption by the year 2100 for Madrid and London under 4.5 climate scenario and small decreases for the 8.5. This study represents one approach towards understanding how building energy consumption will change in the future.
\end{abstract}

Keywords —Energy demand, urban, climate, downscaling

\section{Introduction}

Energy demands in buildings depend significantly on external meteorological conditions, particularly on ambient temperature. Heating, ventilation and air conditioning (HVAC) related energy consumption has been rising in recent years throughout Europe, in particular in Southern Europe. One area directly affected by climate change is the energy consumption for heating and cooling. The impact of global warming on the energy consumption of a building for space heating and cooling depends on the current and future urban climate [1]. Buildings designed according to climatic condition of past years may become increasingly costly to operate and maintain in the present and future.

Roberto San José, Juan L. Pérez, Libia Pérez

Environmental Software and Modelling Group, Computer Science School, Technical University of Madrid (UPM), Madrid, Spain

Rosa M. González

Department of Meteorology and Geophysics, Faculty of Physics,

Complutense University of Madrid (UCM), Ciudad Universitaria, 28040, Madrid, Spain.

Julia Pecci, Antonio Garzón, and Marino Palacios

Indra S.A., C/ Mar Egeo, 4, Pol. Industrial 1, 28830 San Fernando de

Henares, Madrid, Spain
Under the conditions of changing climate, especially in summer, the buildings will consume more energy but with poorer indoor air quality and lower thermal comfort Increase in temperature and extreme weather events, temperature swings, changes in relative humidity and solar radiation should be taken into account to ensure that current and future buildings are able to adapt to these changes [2]. The impact of climate change on heating and cooling energy use in different locations will vary because of their different climates [3]. A detailed analysis of heating and cooling energy use in the future is needed to better understand the impact of climate change on building energy consumption.

It is important, therefore, to develop a better understanding of the relationship between changing climate conditions and energy demand. Climate change scenarios are applied to drive Global Circulation Models (GCM) for prediction of future climate change. IPCC has developed climate change scenarios know as Representative Concentration Pathways (RCPs) including four grades: RCP8.5, RCP6, RCP 4.5 and RCP3-PD. Uncertainty in GCM projections of future climate change generally increases as the spatial scale of interest decreases. Thank you to increases of the computational power, the numerical weather prediction models are now able to approach urban scale resolution. The starting point of dynamical downscaling is typically a set of coarse-resolution largescale meteorological fields (either from a general circulation model, GCM, or from global reanalysis data) which are used to provide the initial, and lateral and surface boundary conditions to a regional climate model (RCM). Typically, the RCM simulation does not feed back into the GCM, but adds regional detail in response to finer-scale forcing (e.g., topography, land use/land cover) as it interacts with the larger-scale atmospheric circulation [4]. In case or the urban areas with building blocks, this resolution is not enough and we need to make Computational Fluid Dynamics (CFD) simulations with meters of spatial resolution. The best boundary and initial conditions should be given for real simulations [5].

A realistic prediction of the future climate is necessary for an energy analysis of buildings. In previous studies for the USA [6] and [7], the UK [8] and, Greece [9], climate change was found to have significant implications for energy consumption in buildings. These studies are regional based and only focus on a few types of buildings, thus could not predict the general impact of climate change on the whole building stock. In our case we will use meteorological information with higher spatial resolution, taking into account the 3D shape of the buildings and sixteen types of buildings. Also this study has been made using two different weather locations: Madrid and London and the analysis was based on the simulated changes for the 2100 relative to the 2011 year under two possible climate scenarios RCP 4.5 and 
RCP 8.5 which are recent climate projections developed by the IPCC.

\section{Material and methods}

\section{A. Urban climate atlas}

Besides building input data, weather data files was also built into the model as an input file. To obtain the hour-byhour energy consumption during the years, data for multiple climatic variables in the form of 8760 hourly records per variable (dry bulb temperature, wet bulb temperature, global solar radiation, wind speed, wind direction, humidity, and pressure) for each year were produce by the Urban Climate Atlas Service for the energy simulations. Weather data is used not only to drive the hour-by-hour response of the building to the climate, but also to size the systems in model, thus affecting capacities, performance curves, and possibly the types of systems to use. All the effects have an impact on the predicted energy use in the model. We are following the next methodology to get the best possible urban meteorological information. The outputs from the global model (CESM) are used as boundary and initial conditions (BSC and ICs) for the regional scale run (Europe). A nesting approach is used from regional $(25 \mathrm{~km})$ to urban level $(1 \mathrm{~km}$.) with the WRF/Chem mode [10] (in the urban level the urban canopy model is activated). The produced 3D fields of meteorological variables are used as BCs and ICs for the street scale runs over the selected urban areas. At this scale the Computational Fluid Dynamics (CFD) model called the MICROSYS is applied with 10 meters of resolution. The urban climate model UCM (urban canopy model) was used inside of the WRF/Chem model for investigating the impact of the climate projections on the local urban climate and air pollution for urban scale level. The UCM is based on the Town Energy Budget approach by Masson [11]. The UCM adopts the turbulent flux resistance network approach in the canyon as described by Harman et al. [12] which takes into account air re-circulating and venting for turbulent heat flux calculation within the canyon. Shadowing is represented in terms of sky view factors that depict the area of each urban surface and the sky that is visible by other urban surfaces (e.g., walls and road). The $\mathrm{UCM}$ is coupled to $\mathrm{WRF} / \mathrm{Chem}$ every simulation physics time step. WRF (meteorological model) and the UCM exchange radiation, sensible heat, latent heat and momentum fluxes, which couples to the WRF planetary boundary layer turbulence closure parameterization. MICROSYS is based into the MIMO CFD model, which takes into account buildings obstacles. The model includes steady threedimensional system of Reynolds equations, $\mathrm{k}-\varepsilon$ model of turbulence.

The IPCC report [13] identifies up to four climate scenarios, $r$ from very strong mitigation scenarios (RCP2.6) to a business-as-usual scenario (RCP8.5). Due to CPUlimitations, we have only simulated climate projections using the RCP 4.5 and 8.5 scenarios. The 8.5 pathway arises from little effort to reduce emissions and represents a failure to curb warming by 2100 . It is characterized by increasing greenhouse gas emissions over time and represents scenarios in the literature leading to high greenhouse gas concentration levels [14]. RCP 4.5 is similar to the lowest-emission scenarios (B1) assessed in the IPCC AR4 ). It is a stabilization scenario where total radiative forcing is stabilized around 2050 by employment of a range of technologies and strategies for reducing greenhouse gas emissions. This can be considered as a weak climate change mitigation scenario [15].

\section{B. Energy simulation}

Building energy usage was estimated by simulating sixteen prototypical buildings with the EnergyPlus model [16]. EnergyPlus is a well-known and highly validated model that is the industry standard. EnergyPlus has been validated in numerous tests from ASHRAE. EnergyPlus is a highly detailed building thermal load simulation program that relies on detailed user inputs. EnergyPlus calculates heating and cooling loads, and energy consumption, using sophisticated calculations of heat gain and heat loss including transient heat conduction though building envelop elements. It also accounts for heat and mass transfer that impact sensible and latent thermal loads due to ventilation and infiltration. Additionally, the model has detailed calculations of heat transfer to or from the ground and comprehensive models of solar gain through the fenestration and opaque envelop components. Building features needed for implementation in EnergyPlus, were taking from the ASHRAE 90.1 Prototype Building Modeling Specifications. Outdoor ventilation air requirements and schedules are defined following the ASHRAE 90.1 Prototype Building Modeling Specifications [17]. Table 1 describes the types of buildings used with the most important building model information.

TABLE I. TYPES OF MODELLED BUILDINGS

\begin{tabular}{|c|c|c|c|c|c|}
\hline Id & Type & $\begin{array}{l}\text { Total } \\
\text { Area } \\
(\mathbf{m} 2) \\
\end{array}$ & $\begin{array}{c}\text { Number } \\
\text { Of } \\
\text { Floors }\end{array}$ & $\begin{array}{l}\text { Window } \\
\text { Fraction }\end{array}$ & $\begin{array}{c}\text { Number } \\
\text { Of } \\
\text { People }\end{array}$ \\
\hline 1 & $\begin{array}{l}\text { High-Rise } \\
\text { Apartment }\end{array}$ & 7837 & 10 & $30 \%$ & 163 \\
\hline 2 & $\begin{array}{l}\text { Mid-Rise } \\
\text { Apartment }\end{array}$ & 3131 & 4 & $20 \%$ & 67 \\
\hline 3 & Hospital & 22428 & 5 & $16 \%$ & 767 \\
\hline 4 & Large Hotel & 11346 & 7 & $30 \%$ & 1494 \\
\hline 5 & Small Hotel & 4013 & 4 & $11 \%$ & 239 \\
\hline 6 & Large Office & 46321 & 12 & $38 \%$ & 2429 \\
\hline 7 & Medium Office & 4980 & 3 & $33 \%$ & 268 \\
\hline 8 & Small Office & 511 & 1 & $20 \%$ & 28 \\
\hline 9 & $\begin{array}{l}\text { Outpatient } \\
\text { Healthcare }\end{array}$ & 3804 & 3 & $20 \%$ & 419 \\
\hline 10 & Fast Food & 232 & 1 & $20 \%$ & 94 \\
\hline 11 & $\begin{array}{c}\text { Sit Down } \\
\text { Restaurant }\end{array}$ & 511 & 1 & $17 \%$ & 288 \\
\hline 12 & $\begin{array}{c}\text { Standalone } \\
\text { Retail }\end{array}$ & 2294 & 1 & $7 \%$ & 370 \\
\hline 13 & Strip mall & 2090 & 1 & $10 \%$ & 337 \\
\hline 14 & $\begin{array}{r}\text { Primary } \\
\text { School } \\
\end{array}$ & 6871 & 1 & $35 \%$ & 1433 \\
\hline 15 & $\begin{array}{l}\text { Secondary } \\
\text { School }\end{array}$ & 19593 & 2 & $33 \%$ & 6095 \\
\hline 16 & $\begin{array}{l}\text { Non-refrigerated } \\
\text { warehouse }\end{array}$ & 4598 & 1 & $1 \%$ & 13 \\
\hline
\end{tabular}

\section{Results}

The first step was to generate high resolution climate data for the future 2100 and present 2011 based on the two IPCC RCP 4.5 and 8.5 climate scenarios over Madrid and 
Proc. of The Fifth Intl. Conf. On Advances in Applied Science and Environmental Engineering - ASEE 2016 Copyright (C) Institute of Research Engineers and Doctors, USA .All rights reserved.

ISBN: 978-1-63248-086-6 doi: 10.15224/ 978-1-63248-086-6-06

London using the modelling system described in the last section. Spatial differences (1 km of spatial resolution) of minimum temperature changes between (the large future) 2100 and 2011 (present) for RCP 4.5 and RCP 8.5 in Madrid calculated with the WRF/Chem modelling system are showed in the Fig 1. With the scenario 4.5 we can observe a decrease in the minimum temperature for the year 2100 up to 2.5 degrees Celsius compared to 2011 in the north and reductions of 1.8 degrees in the center. The climate scenario 8.5 result in an increase of the minimum temperature for the year 2100 up to 1.4 degrees Celsius compared to 2011 in the downtown area. Steady state simulations of airflows over Madrid are showed in the Fig 2 as a examples. It is zooming over $1 \mathrm{~km}$ by $1 \mathrm{~km}$ area to see better the wind complexity. The results come from the CFD model described above with 10 meters of spatial resolution.

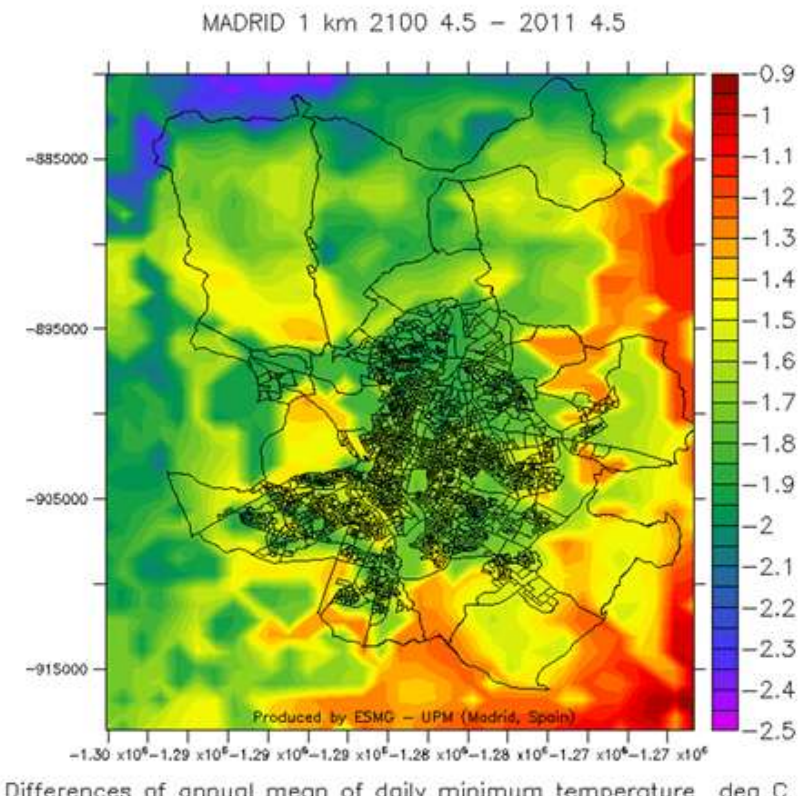

Figure 1. Madrid differences $\left({ }^{\circ} \mathrm{C}\right)$ between 2100 and 2011 spatial distribution (1 kilometer of resolution) of one-year average minimum air temperature with RCP 4.5 (left) and RCP 8.5 (right). Downscaled simulations using WRF-Chem.

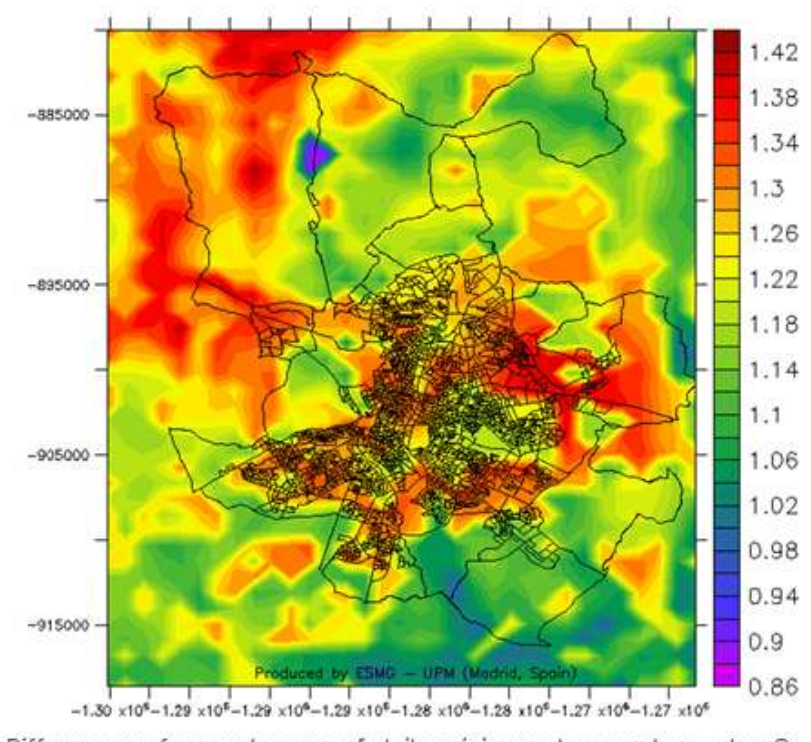

Differences of annugl mean of doily minimum temperature deg
Madrid $10 \mathrm{~m} .21004 .5$

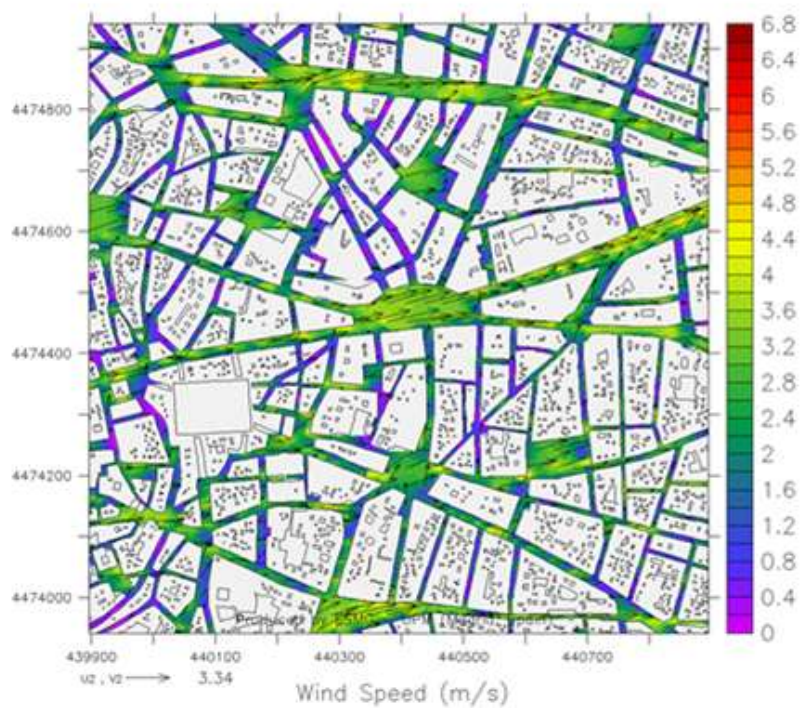

Modrid $10 \mathrm{~m}, 21008.5$

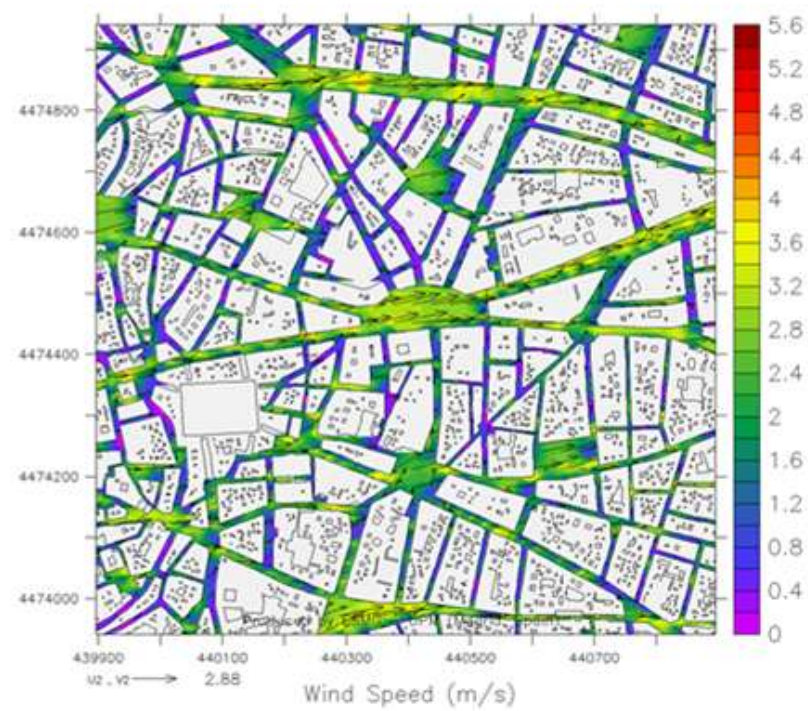

Figure 2. Zomm-in area $(1 \mathrm{~km}$ by $1 \mathrm{~km})$ of Madrid wind vectors and wind speed $(\mathrm{m} / \mathrm{s})$ over Madrid (average winter day) for 2100 under scenario 4.5 (left) and scenario 8.5 (right). 
Proc. of The Fifth Intl. Conf. On Advances in Applied Science and Environmental Engineering - ASEE 2016 Copyright $(\subseteq$ Institute of Research Engineers and Doctors, USA .All rights reserved.

ISBN: 978-1-63248-086-6 doi: 10.15224/ 978-1-63248-086-6-06

We will focus on the results of ort EnergyPlus simulations. We have run 128 simulations (2 years, 2 climate scenarios, 2 cities and 16 building types). Fig. 3 shows the changes $(\%)$ in energy demand for the heating (gas) and electricity (HVAC system) averaged for the sixteen types of buildings for Madrid and Fig. 4 for London by the 2100 as compared to the 2011 under climate scenarios 4.5 and 8.5 plus changes in the monthly average outdoor temperature.The total energy used for cooling and heating will increase only between 18.74 percent for Madrid and 31.36 percent for London under the RCP 4.5 climate scenario. The main reason is a high increase of the gas for heating (36.63\% Madrid and $44.45 \%$ London) because 2100 will be cooler than 2011. The aggregated energy consumption of all averaged buildings including both heating and cooling will only decrease in the RCP 8.5 ($2.72 \%$ Madrid and -8,5\% London) because of the global warming, the heating energy usage will decrease. The cooling energy consumption will increase only during summer months. In general, the percentage of changes in London will be more than that in Madrid, because buildings in London need more energy for heating.

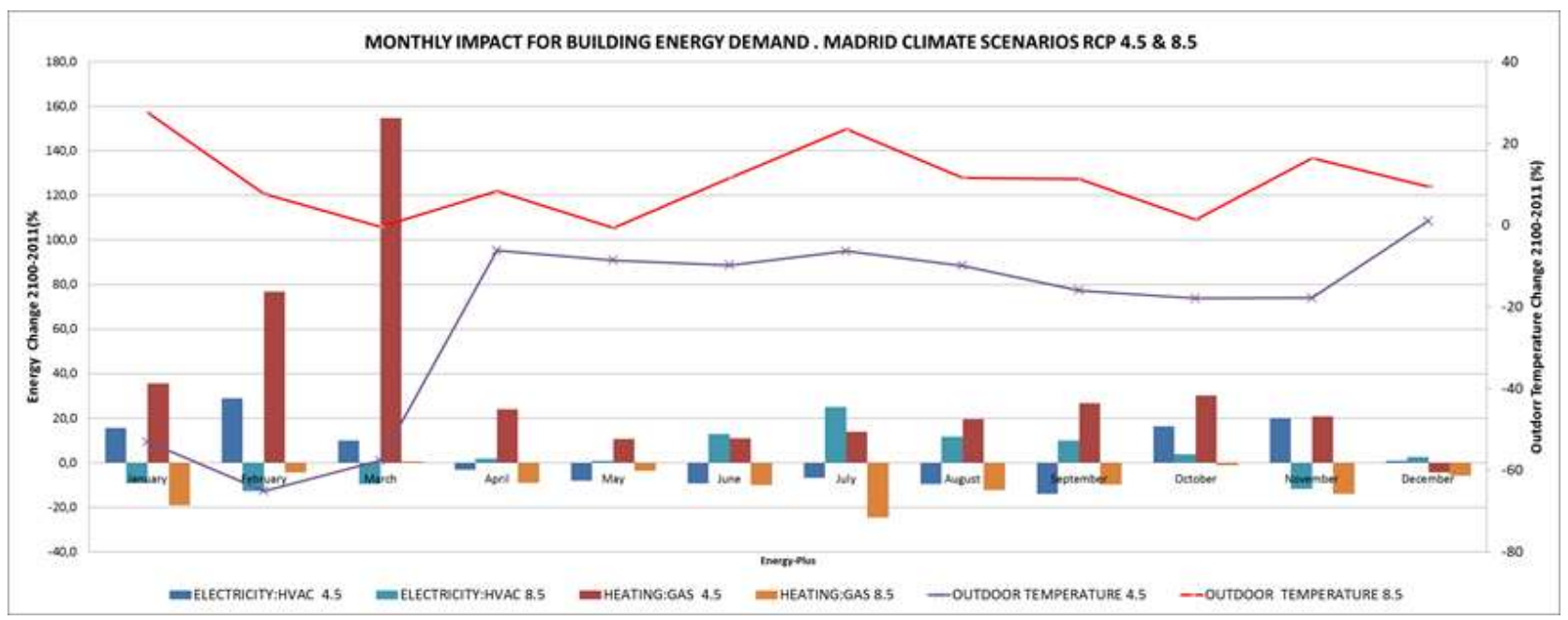

Figure 3. Change 2100-2011 (\%) in monthly energy demand (gas and electricity) and outdoor temperature under two climate scenarios for Madrid.

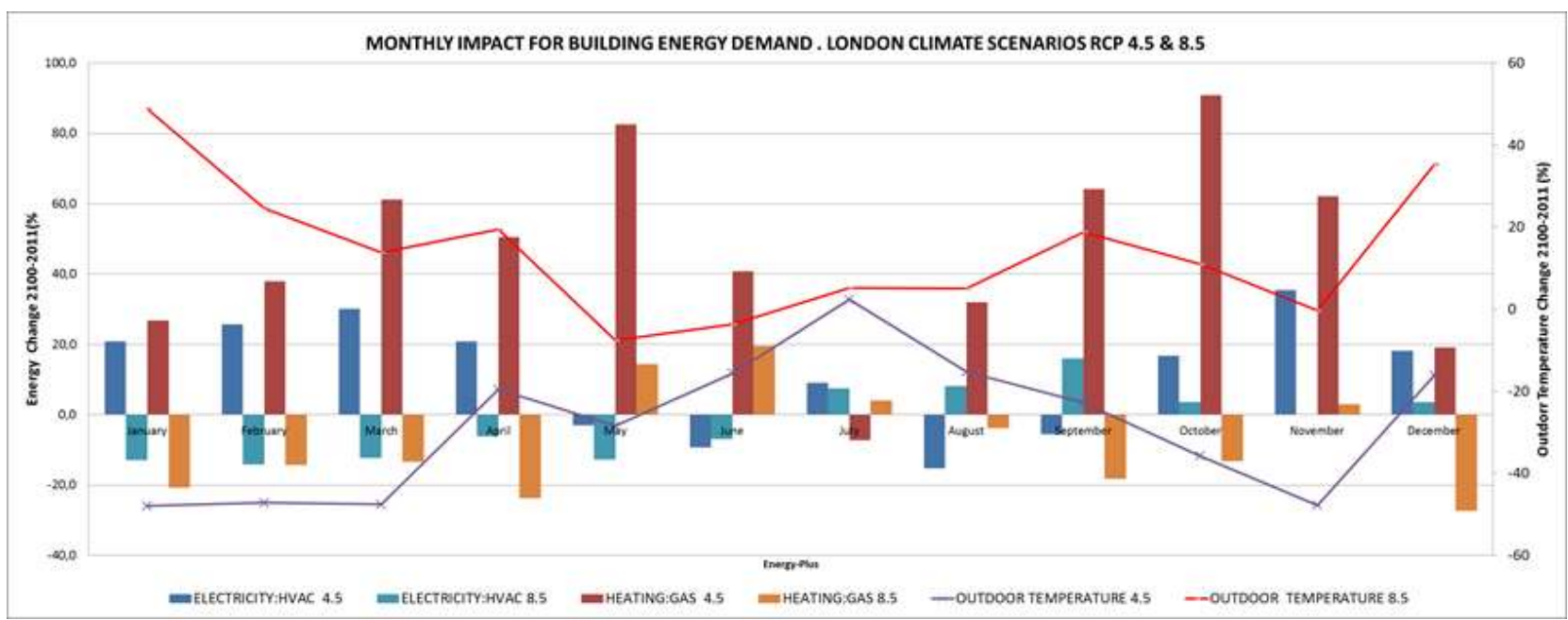

Figure 4. Change 2100-2011 (\%) in monthly energy demand (gas and electricity) and outdoor temperature under two climate scenarios for London

However, the increase and decrease of each type of buildings are different. For example, the heating energy consumption of small office building in Madrid will reduce by almost $48.85 \%$ and $14.23 \%$ for large office. Fig 5 . compares the impact of climate change on HVAC annual total energy demand for the sixteen types of buildings (ids in table 1) in the two cities by the 2100 respect to 2011 under the two possible climate scenarios. Hospital buildings (ids, 3,8 ) and office large buildings (id 6) experience the smallest relative change in energy demand. Restaurants (ids 10 and 11) suffer the most from global climate, primarily because all zones are exposed to the outdoors together with the retail strip malls by the same reason. Heating energy percentage reductions of small buildings are generally larger than that of the big buildings. Small buildings are more sensitive to the weather changes because of their low volume to surface area ratio. 
Proc. of The Fifth Intl. Conf. On Advances in Applied Science and Environmental Engineering - ASEE 2016 Copyright (C) Institute of Research Engineers and Doctors, USA .All rights reserved.

ISBN: 978-1-63248-086-6 doi: 10.15224/ 978-1-63248-086-6-06

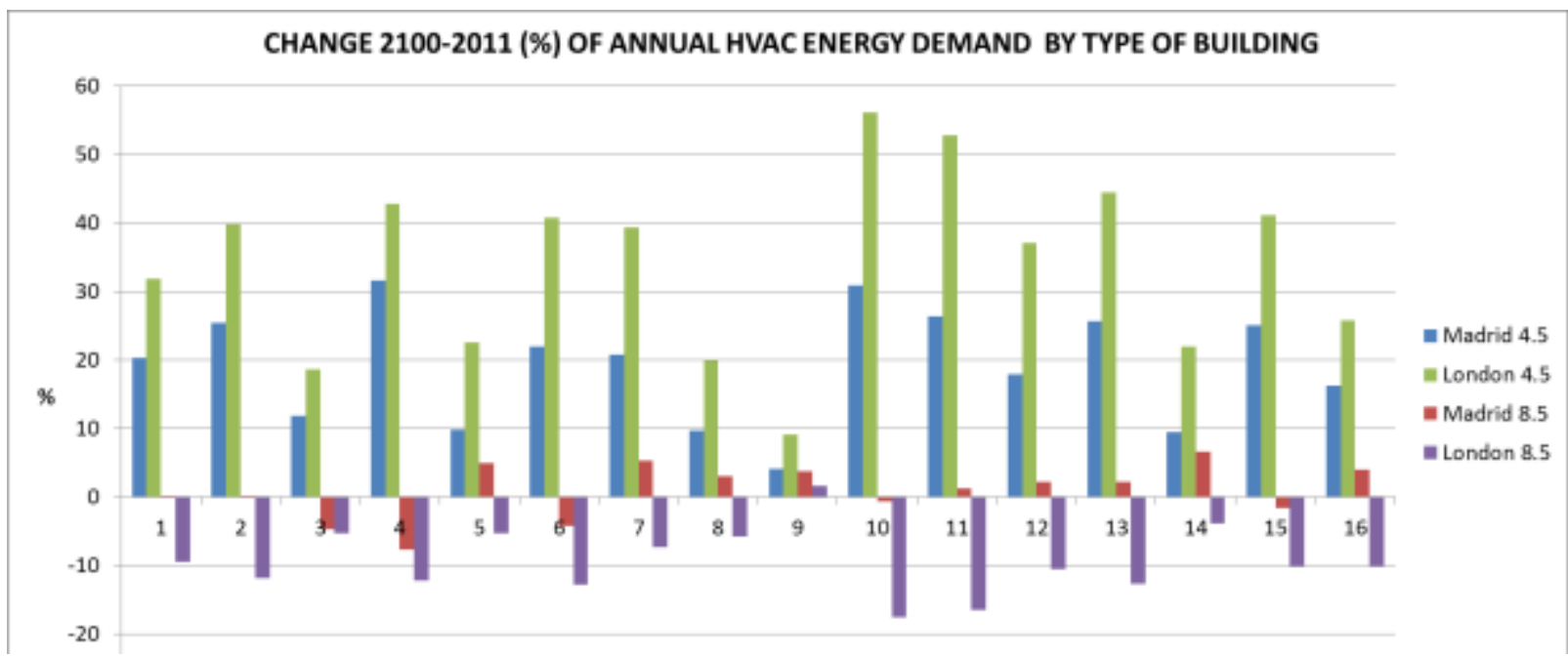

Figure 5. Change in annual HVAC energy demand for sixteen different types of buildins, Madrid and London, RCP 4.5 and RCP 8.5

\section{Conclusions}

Heating and cooling energy consumption of sixteen different types of buildings during 2011 and 2100 in Madrid and London cities, were simulated by using EnergyPlus model under two possible climate projections: RCP 4.5 and RCP 8.5. A micro coupled simulation assessment tool was proposed and applied to study the future climate over three European cities under two IPCC RCP possible scenarios, 4.5 and 8.5. The modelling system tool use a CFD model with boundary and initial conditions from the WRF/Chem model. The downscaled information has been used for studying the impact of future climate projections on buildings energy demand. The findings do support the conclusion that climate change will have a large effect in the building energy consumption.

\section{Acknowledgment}

The UPM authors acknowledge the computer resources and technical assistance provided by the Centro de $\mathrm{Su}-$ percomputación y Visualización de Madrid (CeSViMa). The UPM authors thankfully acknowledge the computer resources, technical expertise and assistance provided by the Red Española de Supercomputación.). We acknowledge the DECUMANUS EU project from EU Space Call FP7SPACE-2013-1 at SPA.20131.1-06. Ordnance Survey data for London: (C) Crown copyright and database rights 2015 OS 100021668 .

\section{References}

[1] G. H. Radhi, Evaluating the potential impact of global warming on the UAE residential buildings - A contribution to reduce the $\mathrm{CO} 2$ emissions. Building and Environment 44 (2009) 2451-2462.

[2] Yau YH, Hasbi S. A review of climate change impacts on commercial buildings and their technical services in the tropics. Renew Sust Energ Rev. 2013; 18: 430-441. doi: 10.1016/j.rser.2012.10.035

[3] D.J. Sailor, Relating residential and commercial sector electricity loads to climate: Evaluating state level sensitivities and vulnerabilities, Energy 26 (2001) 645-657.

[4] Giorgi, F. \& Mearns, L. (1999) Introduction to special section Regional climate modelling revisited. Journal of Geophysical Research, 104 (D6), 6335-6352.

[5] Blocken, B., T. Stathopoulos, P. Saathoff, and X. Wang, Numerical evaluation of pollutant dispersion in the built environment:
Comparisons between models and experiments. J. Wind Eng. Ind. Aerodyn., 96, 1817-1831 (2008).

[6] D.H. Rosenthal, H.K. Gruenspecht, E.A. Moran. Effects of global warming on energy use for space heating and cooling in the United States. Energy J, 16 (1995), pp. 77-96

[7] D.B. Belzer, J.M. Scott, R.D. Sands. Climate change impacts on U.S. commercial building energy consumption: An analysis using sample survey data. Energy Sources, 18 (1996), pp. 177-201

[8] S.E.C. Pretlove, T. Oreszczyn. Climate change: impact on the environmental design of buildings. Proc CIBSE A Build Serv Eng Res Technol, 19 (1998), pp. 55-58

[9] C. Cartalis, A. Synodinou, M. Proedrou, A. Tsangrassoulis, M. Santamouris. Modifications in energy demand in urban areas as a result of climate changes: An assessment for the southeast Mediterranean region. Energy Conversion Manage, 42 (2001), pp. 1656-1674

[10] Grell GA, SE Peckham, R Schmitz, and SA McKeen, G Frost, WC Skamarock, and B Eder. 2005. Fully coupled 'online' chemistry in the WRF model. Atmos. Environ., 39:6957-6976

[11] Masson V (2000) A physically-based scheme for the urban energy budget in atmospheric models. Boundary Layer Meteorol 94: 357397.

[12] Harman I, Barlow J, Belcher S (2004) Scalar fluxes from urban street canyons. Part II: Model. Boundary Layer Meteorol 113: 387-409.

[13] IPCC. Climate Change 2013: The Physical Science Basis; Cambridge University Press: Cambridge, UK; New York, NY, USA, 2013

[14] Riahi, Steven Rose, Paul Runci, Ron Stouffer, Detlef van Vuuren, John Weyant, Tom Wilbanks, Jean Pascal van Ypersele, and Monika Zurek., 2008. Towards New Scenarios for Analysis of Emissions, Climate Change, Impacts, and Response Strategies. Intergovernmental Panel on Climate Change, Geneva, 132 pp.

[15] Smith, Ronald J. Stouffer, Allison M. Thomson, John P. Weyant1 \& Thomas J. Wilbanks, 2010. The next generation of scenarios for climate change research and assessment. Nature 463: 747-756. doi:10.1038/nature08823

[16] Department of Energy, EnergyPlus Engineering Reference: The Reference to EnergyPlus Calculations, Department of Energy, Washington, DC, 2010.

[17] PNNL. 2014. Enhancements to ASHRAE Standard 90.1 Prototype Building Models. Pacific Northwest National Laboratory, Richland, Washington. Available https://www.energycodes.gov/development/commercial/90.1_models.

About Author (s): R. San Jose is professor of the Technical University of Madrid. Director of

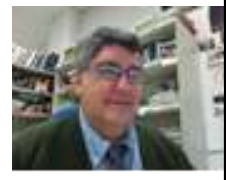
Environmental Software and Modelling Group in the Computer Science School of UPM. He has more than 300 scientific publications in relevant Journal Citation Index Inurnal 